\title{
Effects of Different Densities on Cadmium Accumulation of Cerastium glomeratum
}

\author{
Lijin Lin ${ }^{1}$, Chunyang Liư ${ }^{2}$, Jun Shi ${ }^{3}$ and Ming'an Liao ${ }^{2, *}$ \\ ${ }^{1}$ Institute of Pomology and Olericulture, Sichuan Agricultural University, 611130 Chengdu, Sichuan, China \\ ${ }^{2}$ College of Horticulture, Sichuan Agricultural University, 611130 Chengdu, Sichuan, China \\ ${ }^{3}$ Mianyang Academy of Agricultural Sciences, 621023 Mianyang, Sichuan, China
}

\begin{abstract}
The effects of different densities on cadmium $(\mathrm{Cd})$ accumulation of Cerastium glomeratum were investigated through a pot experiment. The results showed that the root, stem, leaf and shoot biomass of single C. glomeratum decreased with the increase of densities of C. glomeratum seedlings (1, 2, 3, 4 and 5 seedlings in one pot), and the Cd contents in stems, leaves and shoots of C. glomeratum increased. The Cd extraction by whole plant of single C. glomeratum increased when the density was less than 2, and decreased more than that. The Cd extraction by stems, leaves, shoots and whole plant of C. glomeratum in each pot increased with the increase of densities of C. glomeratum seedlings. The maximums of the Cd extraction by stems, leaves, shoots and whole plant of $C$. glomeratum in each pot were $110.55,81.65$, 192.20 and $572.35 \mu \mathrm{g} /$ pot, which increased by $367.05 \%(p<0.05), 348.63 \%(p<0.05), 359.04 \%(p<0.05)$ and $243.59 \%(p<0.05)$, respectively, compared with 1 seedling in one pot. Therefore, highly density could improve phytoremediation efficiency of $C$. glomeratum in Cd-contaminated soil.
\end{abstract}

\section{Introduction}

In agricultural production, the reasonable planting density can increase the yield of crop in per unit area, and improve the using efficiency of land [1-2]. Because of the competition between individual plants for light, water and fertilizer resources, high planting density could result in lower crop yield of per plant, and decrease the yield of crop in per unit area; low planting density can increase single crop yield, but the yield per unit area may reduce because of the small number of individual plant [3-4]. For hyperaccumulator plant, the biomass of per unit area is directly affect their remediation efficiency on heavy metal contaminated soil, and may affect the absorption of heavy metals in soil [5]. The agronomic control measure is an effective increasing yield way, and by regulating the planting density can improve remediation efficiency of hyperaccumulator [6-7]. An appropriate planting density increases the shoot biomass of Sedum plumbizincicola, and increases the amount of zinc and cadmium $(\mathrm{Cd})$ absorption by shoot of Sedum plumbizincicola, which is benefit to phytoremediation of contaminated agricultural soils [8]. Improving the planting density of Brassica juncea can enhance the enrichment of $\mathrm{Cd}$ by plant, promoting the remediation to Cd-contaminated soil [9].

Cerastium glomeratum belongs to Caryophyllaceae, which is an annual herb of common weed growing in winter and spring [10]. In a preliminary study, we found that C. glomeratum is a $\mathrm{Cd}$ accumulator plant [11]. However, the biomass of C. glomeratum is small, needing some methods to increase the biomass of $C$. glomeratum for improving the ability of phytoremediation. In this study, the effects of different densities on $\mathrm{Cd}$ accumulation of C. glomeratum were investigated through a pot experiment, to provide a new method to remediate Cd-contaminated soil of farmland in winter and spring.

\section{Materials and method}

\subsection{Materials}

The inceptisol soil samples were collected from Ya'an campus farm of the Sichuan Agricultural University $\left(29^{\circ} 59^{\prime} \mathrm{N}, 102^{\circ} 59^{\prime} \mathrm{E}\right)$, China, in February 2014 . The basic properties of the soil were the same as reference [12]. Cerastium glomeratum seedlings with two pairs of euphyllas were collected from the Ya'an campus farm (from uncontaminated soil) in March 2014.

\subsection{Experimental design}

The experiment was conducted at the Ya'an campus farm from February to April in 2014. The soil samples were air-dried and passed through a 5-mm sieve. Three kilograms of the air-dried soil was weighed into each polyethylene pot (15 $\mathrm{cm}$ high, $18 \mathrm{~cm}$ in diameter). $\mathrm{Cd}$ was added to soils as $\mathrm{CdCl}_{2} \cdot 2.5 \mathrm{H}_{2} \mathrm{O}$ at $10 \mathrm{mg} / \mathrm{kg}$, and the soil moisture was maintained at $80 \%$ of field capacity for 1 month. The density treatments in the experiment were 1 , 2, 3, 4 and 5 seedlings of C. glomeratum, and each treatment was replicated three times using a completely randomized design with $10-\mathrm{cm}$ spacing between pots. $C$. glomeratum seedlings with corresponding density were transplanted into each pot and the soil moisture content was maintained at $80 \%$ of field capacity from the time the plants were transplanted into the pots until the time the plants were harvested.

\section{3 Sample analysis}

After C. glomeratum had matured (after $30 \mathrm{~d}$ ), the plants were then gently removed from the soil. The roots and shoots of G. parviflora were harvested and washed with tap water. The roots were immersed in $10 \mathrm{mM} / \mathrm{L} \mathrm{HCl}$ for $10 \mathrm{~min}$ to remove $\mathrm{Cd}$ adhering to the root surface. Then, 
the treatments and analyses of plants were described as in reference [12]. Statistical analyses were performed using SPSS 13.0 statistical software (IBM, Chicago, IL, USA). Data were analyzed by one-way analysis of variance with least significant difference at a $5 \%$ confidence level. The translocation factor (TF) is defined as $\mathrm{Cd}$ content in shoot/ Cd content in root [13].

\section{Results and discussion}

\subsection{Biomass of C. glomeratum}

With the increase of densities of C. glomeratum seedlings, the root, stem, leaf and shoot biomass of single $C$. glomeratum decreased (Table 1). When the densities were 2, 3, 4 and 5 seedlings in one pot, the root biomass decreased by $10.83 \%(p<0.05), 24.95 \%(p<0.05)$,
$37.98 \%(p<0.05)$ and $44.77 \%(p<0.05)$ respectively, compared with 1 seedling in one pot, and the shoot biomass decreased by $22.53 \%(p<0.05), 24.62 \%(p<$ $0.05), 29.28 \%(p<0.05)$ and $31.42 \% \quad(p<0.05)$ respectively, compared with 1 seedling in one pot. These results indicate that high density could inhibit the growth of C. glomeratum, which because the competition was between individual plants in limited space. However, the reasonable density could improve the total biomass in unit area, which is consistent with other studies [14-15]. The root/ shoot ratio of $C$. glomeratum increased at first and decreased later with the densities, and the maxmium root/ shoot ratio was the density of 2 (Table 1), indicating that density inhibited growth of C. glomeratum roots. So, under $\mathrm{Cd}$ stress, the root proportion decreased the resistance of C. glomeratum.

Table 1. Biomass of C. glomeratum

\begin{tabular}{|c|c|c|c|c|c|}
\hline Densities & $\begin{array}{c}\text { Roots } \\
\text { (g/plant) }\end{array}$ & $\begin{array}{c}\text { Stems } \\
\text { (g/plant) }\end{array}$ & $\begin{array}{c}\text { Leaves } \\
\text { (g/plant) }\end{array}$ & $\begin{array}{c}\text { Shoots } \\
\text { (g/plant) }\end{array}$ & $\begin{array}{c}\text { Root/ shoot } \\
\text { ratio }\end{array}$ \\
\hline 1 & $0.545 \pm 0.006 \mathrm{a}$ & $1.498 \pm 0.011 \mathrm{a}$ & $0.797 \pm 0.007 \mathrm{a}$ & $2.295 \pm 0.018 \mathrm{a}$ & 0.237 \\
\hline 2 & $0.486 \pm 0.004 \mathrm{~b}$ & $1.141 \pm 0.008 \mathrm{~b}$ & $0.637 \pm 0.004 \mathrm{~b}$ & $1.778 \pm 0.013 \mathrm{~b}$ & 0.273 \\
\hline 3 & $0.409 \pm 0.006 \mathrm{c}$ & $1.104 \pm 0.006 \mathrm{c}$ & $0.626 \pm 0.006 \mathrm{~b}$ & $1.730 \pm 0.011 \mathrm{c}$ & 0.236 \\
\hline 4 & $0.338 \pm 0.008 \mathrm{~d}$ & $1.086 \pm 0.007 \mathrm{~cd}$ & $0.537 \pm 0.008 \mathrm{c}$ & $1.623 \pm 0.016 \mathrm{~d}$ & 0.208 \\
\hline 5 & $0.301 \pm 0.007 \mathrm{e}$ & $1.066 \pm 0.008 \mathrm{~d}$ & $0.508 \pm 0.010 \mathrm{~d}$ & $1.574 \pm 0.018 \mathrm{e}$ & 0.191 \\
\hline
\end{tabular}

\subsection{Photosynthetic pigment contents of C. glomeratum}

With the increase of densities of C. glomeratum seedlings, the contents of chlorophyll a, chlorophyll b, total chlorophyll and carotenoid in C. glomeratum decreased (Table 2). When the densities were 2, 3, 4 and 5 seedlings in one pot, the chlorophyll a content in C. glomeratum decreased by $4.91 \%(p>0.05), 10.27 \%(p<0.05)$, $11.34 \%(p<0.05)$ and $11.70 \%(p<0.05)$ respectively, the chlorophyll b ontent decreased by $2.33 \%(p>0.05)$, $11.33 \%(p>0.05), 12.33 \%(p>0.05)$ and $11.67 \%(p>$ $0.05)$ respectively, the total chlorophyll ontent decreased by $4.37 \%(p>0.05), 10.49 \%(p<0.05), 11.55 \%(p<$ $0.05)$ and $11.69 \%(p<0.05)$ respectively, and the carotenoid content decreased by $6.25 \%(p<0.05)$, $11.00 \%(p<0.05), 12.25 \%(p<0.05)$ and $14.50 \%(p<$ $0.05)$ respectively, compared with 1 seedling in one pot. The other study shows that the carotenoid can receive the surplus energy of excited chlorophyll molecule, and avoids formatting the singlet oxygen, which plays the protective effect of light [16]. So, the high density decreased carotenoid content in C. glomeratum suggesting that the damage of $C$. glomeratum by light enhanced with the increase of growing density. With the increase of densities of $C$. glomeratum seedlings, there was no obvious changes in the chlorophyll a/b (Table 2). The chlorophyll $\mathrm{a} / \mathrm{b}$ was ranked as: 3 seedlings $>4$ seedlings $>1$ seedling $>5$ seedlings $>2$ seedlings.

\section{3 $\mathrm{Cd}$ content in C. glomeratum}

With the increase of densities of C. glomeratum seedlings, the $\mathrm{Cd}$ content in roots of $C$. glomeratum increased when the density was less than 3 , and decreased more than that (Table 3). The maxmium of $\mathrm{Cd}$ content in roots was $319.80 \mathrm{mg} / \mathrm{kg}$ at the density of 3 . However, the $\mathrm{Cd}$ contents in stems, leaves and shoots of C. glomeratum increased. The maxmiums of $\mathrm{Cd}$ content in stems, leaves and shoots were $20.74,32.14,24.42 \mathrm{mg} / \mathrm{kg}$ respectively. When the densities were 2, 3, 4 and 5 seedlings in one pot, the $\mathrm{Cd}$ content in roots increased by $43.29 \%(p<0.05)$, $39.76 \%(p<0.05), 35.26 \%(p<0.05)$ and $10.38 \%(p>$ $0.05)$ respectively, compared with 1 seedling in one pot, and the $\mathrm{Cd}$ content in shoots increased by $6.96 \%(p<$ $0.05), 17.43 \%(p<0.05), 24.51 \%(p<0.05)$ and $33.88 \%$ $(p<0.05)$ respectively, compared with 1 seedling in one pot. The other study shows that the intercropping significantly increased the cadmium contents in each organ of two ecotypes of Bidens pilosa compared with their monoculture respectively [15], which is consistent with this experiment. The translocation factor (TF) of $C$. glomeratum decreased when the density less than 2 , and increased more than that (Table 3), indicating that density promoted $\mathrm{Cd}$ transporting from roots to shoots of $C$. glomeratum in high denssity, which could be benefit to improve the phytoremediation ability of C. glomeratum. 
Table 2. Photosynthetic pigment contents of C. glomeratum

\begin{tabular}{|c|c|c|c|c|c|}
\hline Densities & $\begin{array}{c}\text { Chlorophyll a } \\
(\mathrm{mg} / \mathrm{g})\end{array}$ & $\begin{array}{c}\text { Chlorophyll b } \\
(\mathrm{mg} / \mathrm{g})\end{array}$ & $\begin{array}{c}\text { Total chlorophyll } \\
(\mathrm{mg} / \mathrm{g})\end{array}$ & Chlorophyll a/b & $\begin{array}{c}\text { Carotenoid } \\
(\mathrm{mg} / \mathrm{g})\end{array}$ \\
\hline 1 & $1.120 \pm 0.012 \mathrm{a}$ & $0.300 \pm 0.017 \mathrm{a}$ & $1.420 \pm 0.028 \mathrm{a}$ & 3.733 & $0.400 \pm 0.008 \mathrm{a}$ \\
\hline 2 & $1.065 \pm 0.020 \mathrm{ab}$ & $0.293 \pm 0.005 \mathrm{a}$ & $1.358 \pm 0.025 \mathrm{ab}$ & 3.635 & $0.375 \pm 0.006 \mathrm{~b}$ \\
\hline 3 & $1.005 \pm 0.027 \mathrm{bc}$ & $0.266 \pm 0.024 \mathrm{a}$ & $1.271 \pm 0.051 \mathrm{~b}$ & 3.778 & $0.356 \pm 0.009 \mathrm{bc}$ \\
\hline 4 & $0.993 \pm 0.013 \mathrm{c}$ & $0.263 \pm 0.008 \mathrm{a}$ & $1.256 \pm 0.005 \mathrm{~b}$ & 3.776 & $0.351 \pm 0.004 \mathrm{c}$ \\
\hline 5 & $0.989 \pm 0.042 \mathrm{c}$ & $0.265 \pm 0.027 \mathrm{a}$ & $1.254 \pm 0.069 \mathrm{~b}$ & 3.732 & $0.342 \pm 0.012 \mathrm{c}$ \\
\hline
\end{tabular}

Table 3. Cd contents in C. glomeratum

\begin{tabular}{|c|c|c|c|c|c|}
\hline Densities & $\begin{array}{c}\text { Roots } \\
\mathbf{( m g / k g )}\end{array}$ & $\begin{array}{c}\text { Stems } \\
\mathbf{( m g / k g )}\end{array}$ & $\begin{array}{c}\text { Leaves } \\
\mathbf{( m g} / \mathbf{k g})\end{array}$ & $\begin{array}{c}\text { Shoots } \\
(\mathbf{m g} / \mathbf{k g})\end{array}$ & TF \\
\hline 1 & $228.82 \pm 15.81 \mathrm{~b}$ & $15.80 \pm 0.28 \mathrm{~b}$ & $22.84 \pm 0.93 \mathrm{c}$ & $18.24 \pm 0.50 \mathrm{c}$ & 0.080 \\
\hline 2 & $327.88 \pm 17.14 \mathrm{a}$ & $16.06 \pm 1.33 \mathrm{~b}$ & $25.70 \pm 0.71 \mathrm{bc}$ & $19.51 \pm 1.11 \mathrm{bc}$ & 0.060 \\
\hline 3 & $319.80 \pm 21.50 \mathrm{a}$ & $17.16 \pm 1.19 \mathrm{~b}$ & $28.92 \pm 1.53 \mathrm{ab}$ & $21.42 \pm 1.29 \mathrm{abc}$ & 0.067 \\
\hline 4 & $309.50 \pm 14.85 \mathrm{a}$ & $18.25 \pm 1.06 \mathrm{ab}$ & $31.72 \pm 1.81 \mathrm{a}$ & $22.71 \pm 1.28 \mathrm{ab}$ & 0.073 \\
\hline 5 & $252.58 \pm 10.49 \mathrm{~b}$ & $20.74 \pm 1.78 \mathrm{a}$ & $32.14 \pm 1.22 \mathrm{a}$ & $24.42 \pm 1.57 \mathrm{a}$ & 0.097 \\
\hline
\end{tabular}

\subsection{Cd extraction by single C. glomeratum}

The $\mathrm{Cd}$ extraction by roots of single C. glomeratum increased when the density was less than 2 , and decreased more than that (Table 4). The Cd extraction by roots of single C. glomeratum was ranked as: 2 seedlings $>3$ seedlings $>1$ seedling $>4$ seedlings $>5$ seedlings. The $\mathrm{Cd}$ extraction by stems of single C. glomeratum was ranked as: 5 seedlings $>1$ seedling $>4$ seedlings $>3$ seedlings $>2$ seedlings, and by leaves was 1 seedling $>3$ seedling $>4$ seedlings $>2$ seedlings $>5$ seedlings. When the densities were 2, 3, 4 and 5 seedlings in one pot, the $\mathrm{Cd}$ extraction by shoots of single C. glomeratum were lower than 1 seedling treatment. The $\mathrm{Cd}$ extraction by whole plant of single C. glomeratum was ranked as: 2 seedlings $>3$ seedlings $>1$ seedling $>4$ seedlings $>5$ seedlings. When the densities were 2 and 3 seedlings in one pot, the $\mathrm{Cd}$ extraction by whole plant increased by $16.48 \%(p<0.05)$ and $0.76 \%(p>0.05)$ respectively, and when the densities were 4 and 5 seedlings in one pot, the Cd extraction by whole plant decreased by $15.08 \%$ ( $p<$ $0.05)$ and $31.28 \%(p<0.05)$ respectively, compared with 1 seedling in one pot. Therefore, the densities of 2 and 3 seedlings improved the phytoremediation ability of single C. glomeratum, and the density of 2 was the best.

\subsection{Cd extraction by C. glomeratum in each pot}

When the densities were 2, 3, 4 and 5 seedlings in one pot, the $\mathrm{Cd}$ extraction by roots of $C$. glomeratum in each pot was higher than 1 seedling in one pot, and ranked as: 4 seedlings $>3$ seedlings $>5$ seedlings $>2$ seedlings $>1$ seedling (Table 5). With the increase of densities of $C$. glomeratum seedlings, the Cd extraction by stems, leaves, shoots and whole plant of C. glomeratum in each pot increased. The maxmiums of the Cd extraction by stems, leaves, shoots and whole plant of C. glomeratum in each pot were $110.55,81.65,192.20$ and $572.35 \mu \mathrm{g} / \mathrm{pot}$, which increased by $367.05 \%(p<0.05), 348.63 \%(p<0.05)$, $359.04 \%(p<0.05)$ and $243.59 \%(p<0.05)$, respectively, compared with 1 seedling in one pot. So, highly density could improve phytoremediation efficiency of $C$. glomeratum in Cd-contaminated soil.

\section{Conclusions}

With the increase of densities of C. glomeratum seedlings $(1,2,3,4$ and 5 seedlings in one pot), the root, stem, leaf and shoot biomass of single C. glomeratum decreased, as did in chlorophyll content, and the Cd contents in stems, leaves and shoots of C. glomeratum increased. The maxmiums of $\mathrm{Cd}$ content in stems, leaves and shoots were $20.74,32.14,24.42 \mathrm{mg} / \mathrm{kg}$ respectively. The $\mathrm{Cd}$ extraction by whole plant of single $C$. glomeratum increased when the density was less than 2 , and decreased more than that. The $\mathrm{Cd}$ extraction by stems, leaves, shoots and whole plant of C. glomeratum in each pot increased with the increase of densities of $C$. glomeratum seedlings. The maxmiums of the $\mathrm{Cd}$ extraction by stems, leaves, shoots and whole plant of C. glomeratum in each pot were $110.55,81.65,192.20$ and $572.35 \mu \mathrm{g} /$ pot. Therefore, highly density could improve 
phytoremediation efficiency of $C$. glomeratum in $\mathrm{Cd}-$ contaminated soil.

Table 4. Cd extraction by single C. glomeratum

\begin{tabular}{|c|c|c|c|c|c|}
\hline Densities & $\begin{array}{c}\text { Roots } \\
(\mu \mathrm{g} / \mathrm{plant})\end{array}$ & $\begin{array}{c}\text { Stems } \\
(\mu \mathrm{g} / \mathrm{plant})\end{array}$ & $\begin{array}{c}\text { Leaves } \\
(\mu \mathrm{g} / \mathrm{plant})\end{array}$ & $\begin{array}{c}\text { Shoots } \\
(\mu \mathrm{g} / \mathrm{p} \text { lant })\end{array}$ & $\begin{array}{c}\text { Whole plant } \\
(\mu \mathrm{g} / \mathrm{plant})\end{array}$ \\
\hline 1 & $124.71 \pm 7.33 \mathrm{~b}$ & $23.67 \pm 0.25 \mathrm{a}$ & $18.20 \pm 0.58 \mathrm{a}$ & $41.87 \pm 0.83 \mathrm{a}$ & $166.58 \pm 8.15 \mathrm{~b}$ \\
\hline 2 & $159.35 \pm 6.94 \mathrm{a}$ & $18.32 \pm 1.39 \mathrm{c}$ & $16.37 \pm 0.34 \mathrm{~b}$ & $34.69 \pm 1.73 \mathrm{~b}$ & $194.04 \pm 8.66 \mathrm{a}$ \\
\hline 3 & $130.80 \pm 6.99 \mathrm{~b}$ & $18.94 \pm 1.22 \mathrm{bc}$ & $18.10 \pm 0.79 \mathrm{a}$ & $37.04 \pm 2.01 \mathrm{~b}$ & $167.84 \pm 8.99 \mathrm{~b}$ \\
\hline 4 & $104.61 \pm 2.39 \mathrm{c}$ & $19.82 \pm 1.03 \mathrm{bc}$ & $17.03 \pm 0.70 \mathrm{ab}$ & $36.85 \pm 1.73 \mathrm{~b}$ & $141.46 \pm 4.12 \mathrm{c}$ \\
\hline 5 & $76.03 \pm 1.37 \mathrm{~d}$ & $22.11 \pm 1.73 \mathrm{ab}$ & $16.33 \pm 0.30 \mathrm{~b}$ & $38.44 \pm 2.02 \mathrm{ab}$ & $114.47 \pm 3.39 \mathrm{~d}$ \\
\hline
\end{tabular}

Table 5. Cd extraction by C. glomeratum in each pot

\begin{tabular}{|c|c|c|c|c|c|}
\hline Densities & $\begin{array}{c}\text { Roots } \\
(\boldsymbol{\mu g} / \mathbf{p o t})\end{array}$ & $\begin{array}{c}\text { Stems } \\
(\boldsymbol{\mu g} / \mathbf{p o t})\end{array}$ & $\begin{array}{c}\text { Leaves } \\
(\boldsymbol{\mu g} / \mathbf{p o t})\end{array}$ & $\begin{array}{c}\text { Shoots } \\
(\boldsymbol{\mu g} / \mathbf{p o t})\end{array}$ & $\begin{array}{c}\text { Whole plant } \\
(\boldsymbol{\mu g} / \mathbf{p o t})\end{array}$ \\
\hline 1 & $124.71 \pm 7.33 \mathrm{~d}$ & $23.67 \pm 0.25 \mathrm{e}$ & $18.20 \pm 0.58 \mathrm{e}$ & $41.87 \pm 0.83 \mathrm{e}$ & $166.58 \pm 8.15 \mathrm{~d}$ \\
\hline 2 & $318.70 \pm 13.87 \mathrm{c}$ & $36.64 \pm 2.77 \mathrm{~d}$ & $32.74 \pm 0.68 \mathrm{~d}$ & $69.38 \pm 3.45 \mathrm{~d}$ & $388.08 \pm 17.32 \mathrm{c}$ \\
\hline 3 & $392.40 \pm 20.96 \mathrm{ab}$ & $56.82 \pm 3.65 \mathrm{c}$ & $54.30 \pm 2.38 \mathrm{c}$ & $111.12 \pm 6.02 \mathrm{c}$ & $503.52 \pm 26.98 \mathrm{~b}$ \\
\hline 4 & $418.44 \pm 9.56 \mathrm{a}$ & $79.28 \pm 4.10 \mathrm{~b}$ & $68.12 \pm 2.80 \mathrm{~b}$ & $147.40 \pm 6.90 \mathrm{~b}$ & $565.84 \pm 16.46 \mathrm{a}$ \\
\hline 5 & $380.15 \pm 6.86 \mathrm{~b}$ & $110.55 \pm 8.63 \mathrm{a}$ & $81.65 \pm 1.48 \mathrm{a}$ & $192.20 \pm 10.11 \mathrm{a}$ & $572.35 \pm 16.97 \mathrm{a}$ \\
\hline
\end{tabular}

\section{References}

[1] M.X. Duan, Journal of Maize Science 13, 4 (2005)

[2] W. Liu, J.W. Zhang, P. Lv, J.S. Yang, P. Liu, S.T. Dong, D.H. Li, Q.Q. Sun, Acta Agronomica Sinica 37, 7 (2011)

[3] Y.L. Zhang, K. Xiao, Y.M. Li, Acta Agronomica Sinica 31, 4 (2005)

[4] R. Wang, G.S. Liu, G.S. Ni, Q.W. Bi, L.B. Yang, C.H. Zhen, Acta Agronomica Sinica 35, 12 (2009)

[5] D.C. Su, J.W.C. Wong, Bull. Environ. Contam. Toxicol. 72, 5 (2004)

[6] S.N. Whiting, J.R. Leake, S.P. McGrath, A.J. Baker, Environ. Sci. Technol. 35, 15 (2001)

[7] L. Liu, Q. Zhang, L.L. Hu, J.J. Tang, L.G. Xu, X.T. Yang, J.W.H. Yong, X. Chen, PLoS ONE 7, 8 (2012)

[8] L. Liu, L.H. Wu, N. Li, L.Q. Cui, Z. Li, J.P. Jiang, Y.G. Jiang, X.Y. Qiu, Y.M. Luo, Environmental Science 30, 11 (2009)
[9] W. Wang, B.W. Li, Y.J. Guo, X.B. Li, Journal of Agricultural University of Hebei 32, 2 (2009)

[10]C.L. Tang, P. Ke, D.Q. Lu, Flora reipublicae popularis sinicae (Vol. 26, Science Press, Beijing, China, 1996)

[11] R.P. Hu, J. Shi, T.Y. Huang, L.J. Lin, Journal of Henan Agricultural Sciences 44, 10(2015)

[12] L.J. Lin, Q. Jin, Y.J. Liu, B. Ning, M.A. Liao, L. Luo, Environ. Toxicol. Chem. 33, 11 (2014).

[13]F. Rastmanesh, F. Moore, B. Keshavarzi, Bull. Environ. Contam. Toxicol. 85, 5 (2010)

[14] Y.X. Yang, X.M. Zhu, J.R. Shao, Z.B. Yang, P. Cheng, Journal of Soil and Water Conservation 28, 1 (2014)

[15] K.W. Huang, M.A. Liao, L.J. Lin, Journal of Ecology and Rural Environment 31,5 (2015)

[16] C.P. Sun, J.Z. Zhang, S.J. Duan, Introduction of free radical biology (University of Science and Technology of China Press, Hefei, China, 1999) 